\title{
Classification of Soil Textures Based on Law's Features Extracted from Preprocessing Images on Sequential and Random Windows
}

\author{
R. Shenbagavalli and Dr.K. Ramar
}

\begin{abstract}
Texture analysis has been used for recognizing synthetic and natural textures. Textures are one of the important features in computer vision for image classification and retrieval. An important approach to region description is to quantify its texture content. In this paper, the Soil images has been analyzed using various image pre processing tasks such as Gray level thresholding, Low pass filter, Edge enhancement using Prewitt's Horizontal filtering and then Feature extraction using $3 \times 3$ Law's mask convolution.
\end{abstract}

The features are constructed on preprocessed methods applied on the Soil texture image by considering different types of windows. These features offer a better classification rate. The experimental results on various Soil textures clearly demonstrate the efficiency of the proposed methods.

Keywords--- Soil Texture, Proposed Methods, Experimental Results

\section{INTRODUCTION}

$\mathrm{T}$ HE principal approaches used in image processing to describe the texture of an image region are statistical, geometrical, structural, model-based and signal processing features. In which, the signal processing methods involve transforming original images using filters and calculating the energy of the transformed images[1]These are Law's masks ,Laines - Daubechies wavelets, Fourier transform, Gabor filters.In this paper,we evaluate Law's feature extraction method to describe texture of Soil images using $3 \times 3$ mask convolution. This method is based on masks that aim to filter the images. From each mask, Five classical statistical parameters can be calculated.

\section{A. Laws' Texture Measures}

The texture energy measures developed by K. I. Laws have been used for many diverse applications. T hese measures are computed by first applying small convolution kernels to a digital image, and then performing a non-linear windowing operation. The 2-D convolution kernels typically used for texture discrimination are generated from the following set of one dimensional convolution kernels of length three and five:

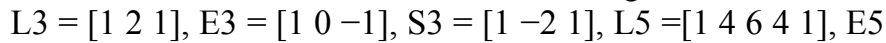

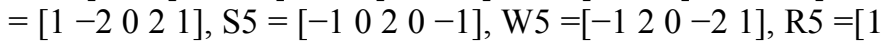
$\left.\begin{array}{lll}-4 & 6 & -4\end{array}\right]$ These mnemonics stand for Level - average grey

R. Shenbagavalli, Asstistant professor, Department of Computer Science, Rani Anna Govt College, Tirunelveli, E-mail: rtillam3000@yahoo.com

Dr.K. Ramar, Principal, Einstein Engineering college, Alangulam level, Edge - extract edge features, Spot - extract spots, Wave - extract wave features, and Ripple - extract ripples . All kernels except L5 and L3 are zero-sum. Convolution of texture with Laws' masks and calculation of energy statistics gives description features of a texture that can be used for texture discrimination[4].

\section{SoIL TeXTURE}

Soil textures are classified by the fractions of each soil separate (sand, silt, and clay) present in a soil. Classifications are typically named for the primary constituent particle size or a combination of the most abundant particles sizes, e.g. "sandy clay" or "silty clay." A fourth term, loam, is used to describe a roughly equal concentration of sand, silt, and clay, and lends to the naming of even more classifications, e.g. "clay loam" or "silt loam." Texture is important, because it affects the movement and availability of water and nutrients in the soil.[9]

The rate of water percolation is another way to describe the texture of soils. Soils percolate water at different rates. Soil should be watered only as much and as fast as the soil can absorb without runoff.[6] Sandy soil absorbs more than two inches of water per hour. It as very porous. Loam soils absorbs from 0.25 to 2 inches per hour. The soil is loose and porous but holds water quite well. Clay soil absorbs less than 0.25 inches of water per hour. Clay soil is dense with few air spaces between particles and holds water.

\section{Methodology}

The present paper computes statistical parameters derived from Law's $3 \times 3$ mask parameters on sequential window (SW) and random window (RW). The size $\mathrm{P} \times \mathrm{Q}$ of the

$\mathrm{SW} / \mathrm{RW}$ is chosen based on the conditions $2 \leq \mathrm{P} \leq \mathrm{M}$ and $2 \leq \mathrm{Q} \leq \mathrm{N}$. Where $\mathrm{P}, \mathrm{Q}$ are the window size and $\mathrm{M}, \mathrm{N}$ are the image size .The starting position of the random window on the image is determined based on the equation (1).

$$
\mathrm{Y}(\mathrm{n}+1)=((\mathrm{a} \times y(n))+\mathrm{b}) \% \mathrm{M}
$$

where $\mathrm{a}$, and $\mathrm{b}$ are the deciding factors for the number of windows.

The RW may contain parts of the other window (overlapped) and the SW does not contain any overlapped windows (non overlapped). One of the features of preprocessing methods is to improve the image information content by suppressing the undesired distortions or enhancements. For this the present paper is applied on the 
following preprocessing methods called Gray level thresholding, Low pass filter,Edge enhancement using Prewitt's Horizontal filtering .

On the preprocessed images the statistical parameters of LAW'S mask are applied they are given by the equations (2)(6). The entire process is given by the algorithm shown in Figure 1.

1. $\quad$ Mean $\mu=\frac{\sum N \text { neighbouring pixels }}{\mathrm{N}}$
2. $\quad \operatorname{ABSM}=\frac{\sum \mathrm{Nabs}(\text { neighbouring pixels })}{\mathrm{N}}$

3. $\operatorname{STD} \sigma=\sqrt{\frac{\sum N(\text { neighbouring pixels }-\mu)^{2}}{\mathrm{~N}}}$

4. Skewness ${ }_{y_{1}}=\frac{\mu_{3}}{\sqrt{\mu_{2}}\left(\mu_{2}\right)}$

5. Kurtosis $\quad v_{2}=\frac{\frac{\mu_{4}}{\mu^{2}}}{\mu_{2}}-3$

\section{B. Algorithm}

1. Read the texture $(\mathrm{M} \times \mathrm{N})$

2. Apply the required preprocessing method on the given texture Method

3. wcount $=($ size of the texture $) /($ size of the window $)$

4. IF Method $=$ sequence

i. $\quad \mathrm{i}=1 ; \mathrm{j}=1 ;$ count $=1$;

ii. Read the window of $\mathrm{P} \times \mathrm{Q}$ from the pixel (i,j) size

iii. From this window, calculate various Law's mask features

If count>wcount

Apply "classification “

Else

$\mathrm{i}=\mathrm{i} \times \mathrm{P}, \mathrm{j}=\mathrm{j} \times \mathrm{Q}$, count $=$ count +1

goto 2

Else "method = random"

i. Set the values of $a, b$ and $M$, count $=1$

ii. $\quad \mathrm{y}(\mathrm{n}+1)=((\mathrm{a} * \mathrm{y}(\mathrm{n}))+\mathrm{b}) \% \mathrm{M}$

iii. From the preprocessed image, read the window of size PxQ from the pixel $y(n+1)$

5. Read the window of $\mathrm{P} \times \mathrm{Q}$ from the pixel $(\mathrm{i}, \mathrm{j})$ size

6. From this window, calculate various Law's mask features

7. If count $>$ wcount Apply "classification “

Else

Count $=$ count +1

Goto 2
Figure 1: Methodology for Soil Texture Classification System by Preprocessing Method

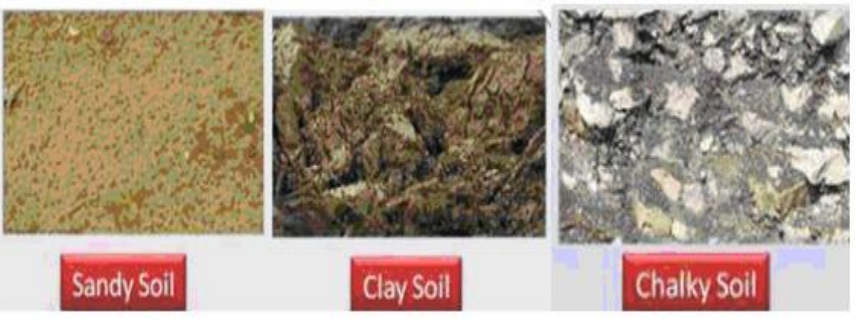

Figure 2: Input images Pictures of Soil - Depending on the Size of the Particles

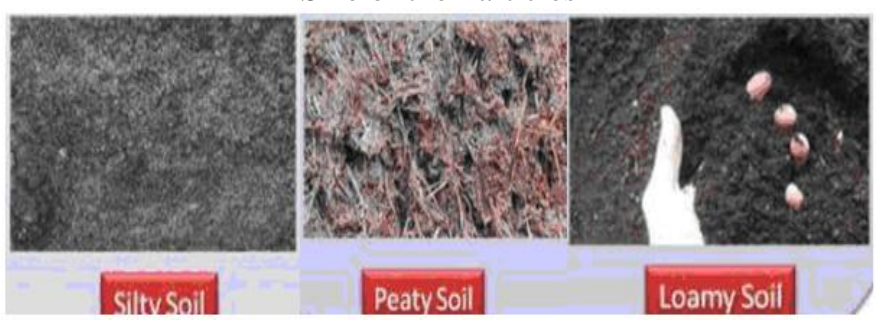

Table 1: Average Texture Classification Rates for RW and SW with Pre-processing

\section{SEQUENCE}

$\begin{array}{lllllll}\text { soil } & \text { LOAMY } & \text { CLAY } & \text { SANDY } & \text { SILTY } & \text { PEATY } & \text { CHALKY } \\ \text { L3E3 } & 100 & 91.19 & 94.261 & 94.96 & 88.114 & 87.3407 \\ \text { E3L3 } & 100 & 92.25 & 93.679 & 94.24 & 91.317 & 88.3818 \\ \text { L3S3 } & 100 & 95.84 & 93.455 & 96.2 & 94.849 & 95.3702 \\ \text { S3L3 } & 100 & 95.35 & 93.693 & 95.67 & 94.305 & 95.035 \\ \text { E3E3 } & 100 & 93 & 93.475 & 96.51 & 92.374 & 93.1004 \\ \text { E3S3 } & 100 & 91.7 & 98.164 & 92.83 & 91.041 & 91.4853 \\ \text { S3E3 } & 100 & 91.08 & 94.303 & 92.01 & 90.589 & 90.8137 \\ \text { S3S3 } & 100 & 94.39 & 97.918 & 94.66 & 93.973 & 94.237\end{array}$

RANDOM

$\begin{array}{lllllll} & \text { LOAMY } & \text { CLAY } & \text { SANDY } & \text { SILTY } & \text { PEATY } & \text { CHALKY } \\ \text { L3E3 } & 100 & 89.89 & 91.585 & 91.19 & 88.8 & 88.1926 \\ \text { E3L3 } & 100 & 89.55 & 91.126 & 90.91 & 88.102 & 86.9398 \\ \text { L3S3 } & 100 & 92.09 & 94.216 & 90.56 & 90.587 & 91.9254 \\ \text { S3L3 } & 100 & 91.6 & 93.161 & 90.44 & 90.843 & 90.5566 \\ \text { E3E3 } & 100 & 96.05 & 92.73 & 95 & 94.764 & 94.8856 \\ \text { E3S3 } & 100 & 93.92 & 96.735 & 95.14 & 93.144 & 93.4267 \\ \text { S3E3 } & 100 & 92.48 & 95.492 & 93.76 & 92.131 & 92.1887 \\ \text { S3S3 } & 100 & 94.84 & 96.993 & 95.27 & 94.413 & 94.6964\end{array}$




\section{RESULTS AND DISCUSSIONS}

The experiments are conducted with 6 texture images of each size $128 \times 128$, collected from soil images [15] as shown in Figure 2. In the first method, a sequential window

(SW) of size $64 \times 64$ is considered. This divides the image into 4 parts and 5 Law's mask

Features are calculated by computing Mean, Abs mean, Standard deviation, Skewness and kurtosis. The average of these features of 4 parts over the set is computed and taken as training set. In the same way a training data is also created for random windows, and they are stored in the texture feature library.

The texture classification is implemented by considering the extracted texture feature from the sample X(loam soil) with the corresponding feature values of all the texture classes $v$ stored in the feature library using the distance vector formula given by the equation (7)

$\mathrm{D}(v)=\sqrt{\sum_{j=0}^{N}[f j(\mathrm{x})-f j(v)]}{ }^{2}$

where $\mathrm{N}$ is the number of features in $\mathrm{f}, \mathrm{fj}(\mathrm{x})$ represents the jth texture feature of the test sample $\mathrm{x}$, while $\mathrm{fj}(v)$ represents the jth feature of the $v$ th texture class in the library.

Table 2: Average Texture Classification Rates for SW with Preprocessing Techniques

$\begin{array}{ccccccc}\text { soil } & \text { LOAMY } & \text { CLAY } & \text { SANDY } & \text { SILTY } & \text { PEATY } & \text { CHALKY } \\ \text { L3E3 } & 100 & 93.184 & 90.0824 & 95.1735 & 92.1532 & 92.0632 \\ \text { E3L3 } & 100 & 94.6232 & 91.0141 & 95.2389 & 89.6275 & 91.7376 \\ \text { L3S3 } & 100 & 99.638 & 97.1926 & 96.9705 & 95.9866 & 94.3035 \\ \text { S3L3 } & 100 & 96.8014 & 95.8292 & 96.0865 & 95.7763 & 92.2236 \\ \text { E3E3 } & 100 & 99.9598 & 99.9256 & 99.9659 & 99.9478 & 99.963 \\ \text { E3S3 } & 100 & 99.9964 & 99.9857 & 99.9885 & 99.9809 & 99.9722 \\ \text { S3E3 } & 100 & 99.9803 & 99.9665 & 99.9754 & 99.9791 & 99.9592 \\ \text { S3S3 } & 100 & 99.9965 & 99.995 & 99.9904 & 99.9902 & 99.9807 \\ \text { AVG } & 100 & 98.0225 & 96.74889 & 97.9237 & 96.6802 & 96.27538 \\ & & & \text { A_MEAN } & & & \\ & \text { LOAMY } & \text { CLAY } & \text { SANDY } & \text { SILTY } & \text { PEATY } & \text { CHALKY } \\ \text { L3E3 } & 100 & 72.3852 & 94.2315 & 95.8198 & 48.7694 & 47.0352 \\ \text { E3L3 } & 100 & 71.6249 & 94.7116 & 91.1854 & 66.3441 & 50.8608 \\ \text { L3S3 } & 100 & 94.9813 & 91.0887 & 97.2033 & 83.3721 & 88.8915 \\ \text { S3L3 } & 100 & 90.5432 & 93.9084 & 96.3699 & 91.888 & 87.6046 \\ \text { E3E3 } & 100 & 94.3477 & 99.6907 & 97.7312 & 90.7896 & 92.5164 \\ \text { E3S3 } & 100 & 97.3009 & 99.5139 & 98.4284 & 94.367 & 96.6442 \\ \text { S3E3 } & 100 & 96.8581 & 99.9566 & 98.3529 & 95.276 & 95.9923 \\ \text { S3S3 } & 100 & 98.3604 & 99.7655 & 98.9913 & 96.9021 & 98.0358 \\ \text { AVG } & 100 & 89.5502 & 96.60836 & 96.76028 & 83.46354 & 82.1976\end{array}$

\begin{tabular}{lcccccc} 
& \multicolumn{5}{c}{ STDD } \\
L3E3 & 100 & 67.9595 & 98.3936 & 86.902 & 25.6826 & 5.4809 \\
E3L3 & 100 & 75.5455 & 99.9256 & 90.9541 & 70.3747 & 29.6358 \\
L3S3 & 100 & 89.6587 & 74.9479 & 97.6649 & 96.7728 & 97.6948 \\
S3L3 & 100 & 93.7717 & 75.3676 & 92.6556 & 84.4105 & 99.6278 \\
E3E3 & 100 & 93.1294 & 99.7121 & 97.3064 & 88.5651 & 89.7351 \\
E3S3 & 100 & 96.8977 & 99.1615 & 98.3172 & 93.36 & 95.8407 \\
S3E3 & 100 & 96.4687 & 99.6261 & 98.4302 & 94.4637 & 95.0686 \\
S3S3 & 100 & 98.0131 & 99.6328 & 98.8783 & 96.2224 & 97.5365 \\
AVG & 100 & 88.9305 & 93.3459 & 95.13859 & 81.23148 & 76.32753 \\
& & & SKEW & & & \\
& LOAMY & CLAY & SANDY & SILTY & PEATY & CHALKY \\
L3E3 & 100 & 98.0722 & 96.719 & 97.4307 & 97.5123 & 97.0431 \\
E3L3 & 100 & 99.0494 & 96.1808 & 97.9694 & 99.0274 & 98.5467 \\
L3S3 & 100 & 99.9164 & 97.8064 & 97.8122 & 98.4629 & 97.9505 \\
S3L3 & 100 & 98.4953 & 97.6895 & 97.8698 & 98.4839 & 97.5854 \\
E3E3 & 100 & 98.7798 & 98.0427 & 99.9612 & 98.6862 & 99.0375 \\
E3S3 & 100 & 98.4656 & 98.5798 & 99.3832 & 98.2913 & 98.4576 \\
S3E3 & 100 & 98.7555 & 99.1891 & 99.5007 & 98.4867 & 98.6749 \\
S3S3 & 100 & 99.1297 & 99.2733 & 99.2758 & 99.4612 & 99.0358 \\
AVG & 100 & 98.833 & 97.93508 & 98.65038 & 98.55149 & 98.29144
\end{tabular}

$\begin{array}{lcccccc} & \text { LOAMY } & \text { CLAY } & \text { SANDY } & \text { SILTY } & \text { PEATY } & \text { CHALKY } \\ \text { L3E3 } & 100 & 90.7079 & 87.6373 & 99.286 & 94.6071 & 98.1194 \\ \text { E3L3 } & 100 & 99.1032 & 78.2112 & 91.4185 & 99.2352 & 94.2371 \\ \text { L3S3 } & 100 & 98.4739 & 96.1237 & 95.9199 & 98.8773 & 99.7248 \\ \text { S3L3 } & 100 & 98.7289 & 97.4332 & 98.3049 & 97.0086 & 98.3071 \\ \text { E3E3 } & 100 & 64.8525 & 60.0471 & 92.8888 & 63.8484 & 71.1439 \\ \text { E3S3 } & 100 & 38.4781 & 99.3883 & 52.4584 & 33.739 & 36.5852 \\ \text { S3E3 } & 100 & 28.4451 & 68.8006 & 39.9018 & 23.2285 & 25.9178 \\ \text { S3S3 } & 100 & 73.0008 & 96.9987 & 74.3411 & 71.1043 & 72.199 \\ \text { AVG } & 100 & 73.9738 & 85.58001 & 80.56493 & 72.70605 & 74.52929\end{array}$

Then the test texture is classified as $v$ th texture, if the distance $\mathrm{D}(v)$ is minimum among all the texture classes available in the library. Based on the distance function the percentage of correct classification for RW and SW are calculated and are represented in table1.

The same is also applied for various preprocessed images and it is shown in table 2 and 3 for RW and SW respectively. Table 1 clearly indicates that on average RW and SW exhibits similar classification rate for the entire statistical measure. Table 2 and 3 clearly indicates the classification rate for the individual statistical measure. The mean and skew processing step has got an advantage, because it exhibits a higher classification rate than entire statistical measure methods for both SW and RW. 
Table 3: Average Texture Classification Rates RW with Preprocessing Techniques

\section{MEAN}

\begin{tabular}{lllllll} 
& LOAMY & CLAY & SANDY & SILTY & PEATY & CHALKY \\
L3E3 & 100 & 93.19665 & 92.57743 & 97.21173 & 95.6606 & 85.03942 \\
E3L3 & 100 & 96.8945 & 93.75475 & 97.63315 & 89.35482 & 86.60502 \\
L3S3 & 100 & 95.77483 & 91.4605 & 93.22218 & 93.8192 & 94.11938 \\
S3L3 & 100 & 95.09715 & 90.21095 & 93.12455 & 94.11338 & 93.5378 \\
E3E3 & 100 & 99.9582 & 99.97633 & 99.99815 & 99.9541 & 99.9202 \\
E3S3 & 100 & 99.99164 & 99.97077 & 99.98047 & 99.9598 & 99.94917 \\
S3E3 & 100 & 99.97363 & 99.9588 & 99.9738 & 99.98834 & 99.9398 \\
S3S3 & 100 & 99.9793 & 99.95598 & 99.9639 & 99.97778 & 99.98153 \\
AVG & 100 & 97.60824 & 95.98319 & 97.63849 & 96.6035 & 94.88654 \\
& & \multicolumn{5}{c}{ A_MEAN } \\
& LOAMY & CLAY & SANDY & SILTY & PEATY & CHALKY \\
L3E3 & 100 & 64.97355 & 95.1433 & 80.86828 & 51.44048 & 51.8525 \\
E3L3 & 100 & 60.2276 & 91.73898 & 78.11823 & 48.9749 & 39.08775 \\
L3S3 & 100 & 84.29135 & 99.0098 & 81.7003 & 74.13608 & 83.54163 \\
S3L3 & 100 & 81.6503 & 94.8632 & 80.65303 & 77.07233 & 74.68188 \\
E3E3 & 100 & 93.52713 & 99.99608 & 97.38073 & 89.96918 & 90.76698 \\
E3S3 & 100 & 95.9064 & 99.51663 & 97.422 & 93.31525 & 94.92453 \\
S3E3 & 100 & 96.31298 & 99.80863 & 98.00133 & 94.689 & 94.82433 \\
S3S3 & 100 & 97.96098 & 99.86345 & 98.8019 & 96.7446 & 97.40068 \\
AVG & 100 & 84.35628 & 97.49251 & 89.11822 & 78.29273 & 78.38503
\end{tabular}

STDD

\begin{tabular}{lllllll} 
& LOAMY & CLAY & SANDY & SILTY & PEATY & CHALKY \\
L3E3 & 100 & 46.856 & 63.78255 & 53.21485 & 34.85283 & 31.6843 \\
E3L3 & 100 & 44.09658 & 58.05383 & 50.37235 & 28.50678 & 12.26535 \\
L3S3 & 100 & 77.91303 & 97.16343 & 61.21328 & 73.05775 & 86.62643 \\
S3L3 & 100 & 80.53835 & 91.1433 & 61.70053 & 75.70113 & 74.34515 \\
E3E3 & 100 & 91.70918 & 99.714 & 96.5342 & 87.33223 & 87.56488 \\
E3S3 & 100 & 95.81148 & 99.55135 & 97.64593 & 92.72 & 94.47968 \\
S3E3 & 100 & 95.47378 & 99.73615 & 97.41583 & 93.31933 & 93.8533 \\
S3S3 & 100 & 97.48118 & 99.74153 & 98.55203 & 96.00028 & 96.70015 \\
AVG & 100 & 78.73494 & 88.61077 & 77.08112 & 72.68629 & 72.1899 \\
& \multicolumn{5}{c}{ SKEW } \\
& LOAMY & CLAY & SANDY & SILTY & PEATY & CHALKY \\
L3E3 & 100 & 98.84578 & 97.34985 & 99.08945 & 98.9841 & 99.0386 \\
E3L3 & 100 & 98.83633 & 97.31898 & 98.87658 & 99.06568 & 98.76228 \\
L3S3 & 100 & 96.00208 & 91.9287 & 93.63505 & 95.209 & 94.77885 \\
S3L3 & 100 & 95.09833 & 91.33128 & 93.36693 & 94.55123 & 94.29113 \\
E3E3 & 100 & 99.8636 & 97.68363 & 99.12585 & 99.70205 & 99.55223 \\
E3S3 & 100 & 98.33693 & 96.90298 & 97.49118 & 98.54778 & 98.6026 \\
S3E3 & 100 & 97.81675 & 95.9488 & 96.85358 & 97.85408 & 97.85933 \\
S3S3 & 100 & 98.39385 & 97.01828 & 97.85635 & 96.84783 & 98.34573 \\
AVG & 100 & 97.8992 & 95.68531 & 97.03687 & 97.59522 & 97.65384
\end{tabular}

\section{KURT}

$\begin{array}{lllllll} & \text { LOAMY } & \text { CLAY } & \text { SANDY } & \text { SILTY } & \text { PEATY } & \text { CHALKY } \\ \text { L3E3 } & 100 & 93.89818 & 80.33958 & 92.04725 & 93.63273 & 92.96943 \\ \text { E3L3 } & 100 & 90.83425 & 80.3878 & 92.32075 & 92.54668 & 92.70978 \\ \text { L3S3 } & 100 & 83.4125 & 86.98598 & 81.16683 & 75.17805 & 75.73378 \\ \text { S3L3 } & 100 & 77.114 & 85.67273 & 79.7244 & 74.71555 & 73.96575 \\ \text { E3E3 } & 100 & 99.31753 & 49.77933 & 82.00915 & 95.62963 & 96.0384 \\ \text { E3S3 } & 100 & 73.0289 & 93.39965 & 83.85773 & 68.4479 & 68.83613 \\ \text { S3E3 } & 100 & 53.88223 & 84.22183 & 68.76095 & 52.22438 & 52.50745 \\ \text { S3S3 } & 100 & 79.55783 & 94.37615 & 82.43235 & 79.20973 & 79.44353 \\ \text { AVG } & 100 & 81.38068 & 81.89538 & 82.78993 & 78.94808 & 69.09509\end{array}$

\section{CONCLUSION}

Various preprocessing methods applied on RW and SW. The RW on preprocessed methods exhibits same percentage of classification as in the case of normal SW method. Though preprocessing is a time consuming process, but the classification rate after preprocessing by mean and skew shows a better result. The preprocessing becomes an essential step when textures are collected from different places and backgrounds for this analysis, the loamy soil has been taken as a test image .Loamy soil is the mixture of clay, sandy and silty soil. From table1 and table 2 data the average classification rate of clay, sandy and silty soil is approximated to loamy soil. But, the chalky and peaty soil rate has long difference from loamy soil. The best results were obtained with the $\mathrm{TR}_{\mathrm{E} 3 \mathrm{E} 3}$ mask.

\section{REFERENCE}

[1] Alaa Noori Mazher, Dr. Alyaa Hussain Ali, "Texture Analysis of Brodatz Images Using Statistical Methods"

[2] Evaluation of Texture Methods for Image Analysis Mona Sharma ,Markos Markou ,Sameer Singh

[3] Wavelet Based Features for Texture Classification P.S.Hiremath*, S.Shivashankar $\dagger$,Dept. of P.G.Studies and Research in Computer Science, Gulbarga University,

[4] Texture segmentation: Co-occurrence matrix and Laws' texture masks methods Guillaume Lema^1tre - Miroslav Rodojevi'c ,Heriot-Watt University, Universitat de Girona, Universit'e de Bourgogne

[5] IDL Tutorial Advanced Image Processing,Copyright @ 2008 ITT Visual Information Solutions

[6] Role of Soil in Groundwater Protection By Carl F. Engle, Craig G. Cogger, and Robert G. Stevens

[7] Determining Composition of Grain Mixtures by Texture Classification Based on Feature Distributions.Timo Ojala, Matti Pietikäinen, and Jarkko Nisula Characteristics of Soil by Randy Scott, Consulting Rosarian Woodbridge.

[8] Loam From Wikipedia, the free encyclopedia

[9] Classification of Textures Based on Features Extracted from Preprocessing Images on Random Windows by B.V. Ramana Reddy, A. Suresh, M. Radhika Mani, and V. Vijaya Kumar 